\title{
El Factor Pinochet Elites y Democracia
}

Freddy Timmermann

Sociologo

El autor aborda la temática denominada "el factor Pinochet", más allá de su presencia física directa en los espacios de poder, sino más bien como una herencia política de su régimen dictatorial, en alianzas con las élites políticas y económicas de Chile. Como se señala, pareciera ser que hemos heredado una cultura autoritaria que traspasa las fronteras temporales del período del régimen militar y se instala en una debilitada democracia actual.

Palabras clave

Pinochet / autoritarismo / élites / poder / política 


\section{Abstract}

The author approaches the topic denominated "Pinochet factor", beyond his direct physical presence in the spaces of power, but rather like a political inheritance of his dictatorial regime, in alliances with the political and economic elites of Chile. As it is shown, it seemed to be that we have inherited an authoritarian culture that transfers the temporary borders of the period of the military regime and it settles in a weakened present democracy.

\section{Keywords}

Pinochet / authoritarianism / elites / power / politics 
partir del estudio de los dispositivos de poder de
Augusto Pinochet desarrollados entre los años 1973 como la tendencia de un individuo de escasa cultura introspectiva a mantener la estabilidad en el control del espacio de poder que posee, ejerciendo la fuerza por sobre el poder mayormente aunque no exclusivamente, convirtiendo en objetos de manipulación los contextos teóricos históricos y las realidades humanas presentes en las coyunturas en que está inserto, por medio de una "ideología formal" flexible; desarrollando una conducta instrumental en que los medios son los fines, y el fin es el poder por sí mismo; en una acción constante que abarca también sus microcoyunturas cotidianas, siempre inserto en una tensión psíquica de competencia extrema por estos espacios de poder en que no se descarta la anulación del rival, de cualquier tipo que ésta sea, tendiendo a operar como un "superviviente" ${ }^{2}$,

1 Los fundamentos teóricos e históricos de esta caracterización se encuentran el "El Factor Pinochet. Elites y Dispositivos de Poder. Chile 1973 - 1980”, Tesis de Magíster en Historia de Chile, Facultad de Filosofía y Humanidades, Universidad de Chile, 2003. En publicación.

2 Si en 1973, 1975 y 1977 se desarrollan las "coyunturas" principales de la "estructura" que analizamos, el dispositivo de poder de Augusto Pinochet, entre la primera y la segunda, ha establecido uno que en su esencia - el uso de la violencia - no variará, transformándose en un "superviviente", porque "el momento de sobrevivir es el momento del poder" y porque "la forma más baja de la supervivencia es la del matar" (Canetti, Elías. Masa y Poder. Alianza Editorial, Madrid, 1995, pp. 223 - 228. 
involucrando elementos a-racionales ${ }^{3}$ como el miedo, el dolor, la ambición, el odio, la venganza, etc.. Tiene la certeza, no siempre explícita, de construir desde la inmanencia para la inmanencia, aunque amparado en un sentido de trascendencia católico centrado en sí mismo que adquiere un carácter heroico.

\section{Autoritarismo y Democracia}

Se perfila un contexto de acción que muestra un tipo de sociedad con un profundo arraigo autoritario en las elites gobernantes que compartieron con él el poder, lo que ayuda a comprender hasta qué punto el autoritarismo en Chile es un problema de profundo significado histórico. El autoritarismo en Chile tiene un desarrollo claro, al menos, desde mediados del siglo XVIII, momento en que la elite agraria comienza a controlar no sólo los ámbitos rurales sino también los espacios "urbanos", ante el vacío de poder que el dominio español ya presentaba. El Estado "portaliano" recoge esta tendencia temprana por parte de la autoridad al establecer un orden sin consultar a los gobernados ${ }^{4}$.

3 Pinochet utiliza elementos en la proyección de sus dispositivos de poder que no forman necesariamente un procedimiento técnico pues no los razona sistemáticamente, o bien los razona en función de otros factores que no constituyen una doctrina de pensamiento. Los denominamos elementos a-racionales. Configuran otra racionalidad de poder, con grados distintos de inserción en el tiempo y, por lo tanto, de certidumbre en el manejo de determinadas situaciones. A ratos, irrumpen impensadamente perturbando los diseños más racionales de control. Es tal su presencia en los dispositivos de poder de Augusto Pinochet que no pueden soslayarse.

4 Ana María Stuven estudia para el siglo XIX el establecimiento de un parámetro de “orden” en "Una Aproximación a la Cultura Política de la Elite Chilena: Concepto y Valoración del Orden Social (1830-1860)" (Estudios Públicos N 66, 1997); Mario Góngora, la formación del Estado, en su Ensayo Histórico Sobre la Noción de Estado en Chile en los Siglos XIX y XX (Editorial Universitaria, 1986); Edwards, para demostrar que en la elite ha nacido un "espíritu" propio, escribe La Fronda Aristocrática en Chile (Editorial Universitaria, 1991). En mi estudio "Liberalismo, Educación y Poder. Chile, 1830 - 1930" (Revista de Historia y Geografía, № 17, Universidad Católica Cardenal Raúl Silva Henríquez, 2003) analizo las relaciones que el autoritarismo establece con el liberalismo europeo y el disciplinamiento social que de allí se deriva. 
Sol Serrano ha mostrado para el siglo XX las restricciones electorales que permiten sostener un autoritarismo democrático hasta 1973; John Friedmann y Thomas Lackington, como bajo un "sistema pluralista de negociaciones" "los grupos dominantes formuladores de decisiones... comparten un amplio acuerdo respecto a la mantención y aún a la modificación del sistema, pero una oposición general a la transformación del sistema", y Genaro Arriagada, para la década del sesenta, la existencia concreta de una "oligarquía patronal" de enorme influencia en los grupos de poder económico del período 5 .

Culturalmente, es una tendencia que persiste hasta hoy en la acción política, en la administración de las organizaciones públicas y privadas, en la vida familiar $y$, en general, en nuestra cultura, tendencia que concede una extraordinaria importancia al rol de la autoridad y al respeto por ella ${ }^{6}$, razón que lleva a algunos politólogos a afirmar que nuestra sociedad es mayormente premoderna, es decir, incapaz de asegurar a sus componentes sociales las estructuras para que éstos produzcan un orden social propio, por lo que éstos sólo viven inmersos en un orden concedido y no en uno autónomamente producido ${ }^{7}$.

5 Serrano, Sol. "La Democracia que Tuvimos, la Democracia que no fue". Revista de Sociología, Departamento de Sociología, Universidad de Chile, n 14, 2000, pp. 117 - 120. Friedmann, John - Lackington, Thomas. "La Hiperurbanización y el Desarrollo Nacional de Chile" (En: Godoy, Hernán. Estructura Social de Chile, Editorial Universitaria, Santiago, 1971, pp. 426-438). Arriagada, Genaro. La Oligarquía Patronal Chilena. Ediciones Nueva Universidad, Universidad Católica de Chile, Santiago, 1970.

6 Larraín, Jorge. La Trayectoria Latinoamericana a la Modernidad, Editorial Andrés Bello, Santiago, 1996, p. 327.

7 Gauchet, Marcel, Le désenchantement du monde, 1985 (citado por Lechner, Nortbert. "Los Patios Interiores de la Democracia". FLACSO, Santiago, 1988, p. 168). 


\section{La Pesadilla}

Un síntoma actual de lo mencionado es el hecho de demonizar a Pinochet, de tratarlo como una "pesadilla" que pasó por nuestro país ${ }^{8}$, razonamiento que es usado por no pocos como el elemento fundamental para comprender cuánto aconteció en el régimen militar, sin pretender discutir ni superar las razones que existieron para que ello ocurriera y ocultando un hecho esencial en este sentido: que el régimen militar contó con el respaldo "de una considerable parte de la población" ${ }^{\prime \prime}$ y, en especial, de una élite cívico-militar. Interesa resaltar, por un lado, que esta percepción refleja un problema no resuelto como sociedad y como individuos en cuanto a la relación con la autoridad se refiere porque, no se debe olvidar, las pesadillas existen en uno, no fuera de uno ${ }^{10}$.

Por otro, que hasta las pesadillas requieren un contexto donde desarrollarse. Pensamos, al respecto, que los elementos del dispositivo de poder de Augusto Pinochet generan, al mismo tiempo que recogen, en su desarrollo el contexto que el mismo "Factor Pinochet" posibilita. Sería interesante preguntarse, ya desaparecido Pinochet de la arena política, si quienes formaron parte de aquel "contexto de pesadilla" ya pasaron por nuestro país o aún se constituyen, en función de cuanto aprendieron y aprehendieron en el período en estudio, a su vez en pesadillas no de hechos pasados sino presentes, prolongando en cierta medida el "Factor Pinochet", es decir, la emergencia de un "superviviente" ya no en un ambiente psíquico de guerra sino política y económicamente extremadamente competitivo; en el fondo, en otro tipo de guerra.

8 Incluso en una fecha tan cercana como noviembre del 2004 lo escuchamos en "Chilevisión Noticias" en las palabras de Carlos Ominami. Ello se ha expresado para el imaginario visual en la fotografía en blanco y negro del Te Deum de 1973: rostro serio, rígido, lentes oscuros, uniforme militar.

9 Huneeus, Carlos. El Régimen de Pinochet. Editorial Sudamericana, Santiago, 2000, pp. 37, 352, 389.

10 Ascanio Cavallo. En "La Belleza de Pensar", Canal 13 de Televisión, Universidad Católica, 1999. 


\section{El Nuevo Héroe}

La proyección histórica inmediata del "Factor Pinochet" no requiere de un tipo especial de individuo. Hannah Arendt, en el juicio que se siguió a Adolf Eichmann en Jerusalén, se rindió ante la evidencia de que, a pesar de todos los esfuerzos desplegados por la acusación para diabolizar a este hombre, él aparece como un ser profundamente mediocre, ordinario, común, cuando el mal del que es responsable es uno de los más grandes de la historia de la humanidad. En este sentido, el mal que ilustra Eichmann es "trivial" y no sólo "radical" o inhumano.

Precisamente, porque es tan fácil y porque no exige cualidades humanas excepcionales es por lo que este mal es particularmente peligroso: por poco que el viento sople del "buen" lado, se propagará a la velocidad del fuego ${ }^{11}$. Los dispositivos de poder estudiados en Augusto Pinochet han mostrado a un sujeto con un instinto-poder y una habilidad política particulares, así como una enorme flexibilidad de sus ideologías que, actuando inicialmente en un determinado contexto de crisis - las semanas finales de agosto y las iniciales de septiembre de 1973 - y posteriormente en uno extremadamente autoritario, pudo sobrevivir, no a un fanático de origen, aunque posteriormente pueda adquirir notorios rasgos de éste ${ }^{12}$; tampoco han mostrado a un portador de alguna patología psíquica extrema. Si bien existe un límite para la gente que puede matar por odio o por el gusto de la masacre, no hay tal para la cantidad que

11 Todorov, Tzvetan. Frente al Límite. Siglo XXI Editores, México, 1993, p. 133.

12 "La cualidad del fanatismo se adquiere con extrema rapidez porque no requiere colaboración del resto de la personalidad. Puede llegar a prescindir de estructuras en desarrollo y temporariamente nutrirse a sí mismo. Pienso que a esta razón se debe la dificultad que conlleva la tarea de abandonar el pensamiento autocrático, ya que el desarrollo del pensamiento tolerante - en cambio - se realiza sobre una base de gran lentitud y se acompaña de cierto grado de penuria, habitualmente conceptualizada como "dolor psíquico". Agregan: "Es posible que la estructura fanática no tolere un cambio catastrófico sin una destrucción violenta y global que no admita ningún continente" (Senet de Gazzano - Sor, Darío. Fanatismo, Editorial Ananké, Buenos Aires, 1993, pp. 262, 263). 
se pueda matar de manera fría y sistemática en nombre del imperativo categórico militar. En este último caso, la explicación causal de semejante conducta no debe buscarse sólo en las características del individuo, sino en las de la sociedad que impone tales "imperativos categóricos", es decir, la explicación no es psicológica o individual, sino política y social ${ }^{13}$.

Pinochet no siguió el camino del "héroe" para alcanzar la invulnerabilidad que su "ideología formal" militar exigía, aquél de permitir que el peligro se le acercase lo más posible jugándose el todo por el todo al enfrentarlo, seleccionando de todas las situaciones posibles la que entraña un peligro mayor si técnicamente procedía; hemos visto que su "ideología formal", al transformarse en "ideología total"14, se lo impidió. Pinochet procuró alejar siempre de sí el peligro interponiendo grandes espacios que podría abarcar y vigilar mediante la DINA y la CNI.

Se ocultó ante el peligro y lo desterró, legitimándose en función de un héroe construido por los intérpretes de Dios que lo rodeaban o por el mito que las élites le construyen, no por uno que tuviera como base una historia concreta, real ${ }^{15}$. El "Factor Pinochet" plantea un heroísmo ajeno a la guerra, pues la evita, o la propone con otro carácter. En esto se muestra moderno, pues hoy la guerra es condenada por casi todos. Las antiguas virtudes militares ya no son apreciadas y morir por la patria ya no tienta al mundo.

13 Todorov, Tzvetan. Frente..., op. cit., pp. 131, 132. La palabra en cursiva es mía, discrepando en este punto con Todorov.

14 La ideología que nosotros llamaremos "formal", es aquella que denota un "cuerpo de conocimientos" o "teoría" o "doctrina" acerca de la sociedad o historia, y que no necesariamente debe estar vinculada con los intereses colectivos del grupo social que la crea o sustenta. Si a esta "ideología formal" sumamos una serie de elementos a-racionales como los miedos, dolores, etc., ya hablamos de "ideología total". No debemos olvidar que esta "ideología total" es más inestable que la "ideología formal" en el tiempo (Merino, Augusto. El Concepto de Ideología. Editorial Universitaria, Santiago, 1987, pp. 11-13. Seguimos sus ideas al respecto. La frase en cursiva, así como los términos de ideología "formal" e "ideología total", son variaciones nuestras).

15 Por ejemplo, El Día Decisivo. 11 de Septiembre de 1973, escrito supuestamente por Augusto Pinochet (Editorial Andrés Bello, 1980). 
La guerra moderna es distinta de los enfrentamientos de un héroe antiguo como, por ejemplo Aquiles. La perfección de las armas, no el coraje o el poder de los combatientes decide la suerte en una batalla; el mérito de una victoria depende de un ingeniero que está tranquilamente sentado en su despacho más que de un soldado ubicado en la primera línea. Estas últimas ya no existen; tampoco el contacto con el adversario. La amenaza de muerte, por lo tanto, ya no afecta las acciones del héroe moderno, pues éste no está dispuesto a arriesgar su vida para hacerse reconocer como tal. No es un ser excepcional marcado por un nacimiento milagroso, por un trato con los dioses o con las bestias; es una persona como todas, no aislada del tejido social.

Si bien en su habitat de poder no cultiva el mundo físico sino político, económico o intelectual, de éste no han desaparecido algunas virtudes militares como la dureza y el espíritu combativo - en las negociaciones con los aliados o en los conflictos con los adversarios -, la habilidad táctica o estratégica - en la simulación de los objetivos, los cambios de alianzas, o en la capacidad para prever los movimientos de los otros -, eficacia - en la rapidez de decisiones, la elección adecuada de medio -, y, por sobre todo, la capacidad de ganar, de ser el mejor, de conducir la empresa iniciada al éxito. A diferencia de los héroes que se sacrifican por la patria o por un ideal, su heredero moderno no somete su actividad a un fin que le será exterior. En este sentido, el apetito de poder no es una cualidad transitiva, no conduce a nada más allá de sí mismo, no se aspira a él para obtener no sé qué beneficio o para servir a un ideal cualquiera; se busca el poder por el poder; es un fin, no un medio ${ }^{16}$.

16 Para construir este perfil del héroe actual, he seguido casi literalmente las ideas de Tzvetan Todorov (Frente..., op. cit., pp. 53 - 65). 


\section{Poder, Técnica, Utopía}

El héroe que expone el "Factor Pinochet" es un caudillo de sí mismo, surgido en un momento en que las ideologías que lo situaban al servicio del bien común se extinguían, lo que responde -además- a un tiempo de dependencia que transita de un período de modernizaciones a otro. Por una parte, hereda rasgos que pertenecen a una etapa neocolonial, caracterizada por la "metropolización" de elites que deben no sólo reproducir conceptos y actitudes propios de un centro cultural, sino también remodelar su entorno social para hacerlo igual a un centro considerado paradigma de "modernidad". Ingresa, al mismo tiempo, a un período en el que las formas de organización económica y tecnológica de los centros de poder evolucionan hacia una estructura transnacional, caracterizada por la interacción de intereses privados que trascienden a los de los gobiernos y se conjugan en una red de relaciones no estatales; por ello, estas elites tienen "perspectivas distorsionadas y ajenas de los procesos culturales y políticos propios de las sociedades a las cuales se integran".

Pero también este período hereda, por otra parte, tanto para las elites de izquierda como para las de derecha, el deseo de "arrasar con todo lo que venía antes", en el sentido que expone Marshall Berman: para alcanzar "un punto radicalmente nuevo de partida", para establecer un verdadero presente, lo que refuerza el espíritu adversario y la actitud de minoría perseguida ${ }^{17}$; unos lo adquieren procurando imitar la revolución cubana y sus variantes ${ }^{18}$; otros, los Chicago Boys, en el posterior experimento neoliberal; y otros, finalmente, en los contextos que la DINA y la CNI establecen en Chile y también fuera de Chile para quienes disienten con el régimen militar.

17 Valdés, Juan Gabriel. La Escuela de Chicago: Operación Chile, Ediciones B Grupo Z, Buenos Aires, 1989, pp. 315, 316. Algunas de estas ideas las adaptamos a nuestros fines.

18 Ver: Rodríguez Elizondo, José. Crisis y Renovación de las Izquierdas. Editorial Andrés Bello, Santiago, pp. $227-306$. 
Para las élites, al comenzar a desaparecer las tradiciones de poder dominantes, las dos últimas décadas del siglo XX que tendían al logro del bien común a partir del Estado Benefactor inserto en la tendencia "fordista" ${ }^{19}$, y, en forma más restringida, en el corporativismo comunitario y en el nacionalismo - la desaparición de algunas "ideologías e "ismos", uno de los desarraigos que van experimentando-, cada uno de sus miembros inaugura y recrea a la vez su propia tradición de poder no ya en un marco extremo como el que impuso el régimen militar - de sobrevivencia física y psíquica para toda forma de disidencia - pero sí de sobrevivencia política y económica.

A muchos intelectuales que habían vivido la "democracia burguesa" como una ilusión o manipulación, incapaz de asumir los imperativos del desarrollo, la dictadura les enseña el carácter político de las cuestiones supuestamente técnicas. Si no hay una "verdad" establecida o hábitos reconocidos por todos, entonces se hace indispensable instaurar "reglas de juego" que permitan defender los "intereses vitales" y negociar un acuerdo sobre las opiniones en pugna". Finalmente, "Tanto la tradición marxista como la doctrina militar y el pensamiento neoliberal comparten (con signos diferentes) un mismo esquema interpretativo: el presente como una "transición" hacia la realización de una utopía. Que el futuro sea imaginado como mercado o como sociedad sin clases lleva, a fin de cuentas, a un orden post-político y a la "abolición de la política" como una meta factible, razón por lo que la acción política presente tiene un carácter exclusivamente instrumental" ${ }^{20}$.

19 Tironi, Ernesto. "Autoritarismo, Modernización y Marginalidad. El Caso de Chile 1973 - 1989”, Ediciones Sur, 1989. Es importante resaltar que la derecha ha logrado, sin embargo, rearticular estas en función de las nuevas coyunturas a partir de 1973 imponiéndose las tendencias neoliberales de percepción social. Ver: Cristi, Renato. "La Síntesis Conservadora de los Años 70" (en: Cristi, Renato - Ruiz, Carlos. "El Pensamiento Conservador en Chile". Editorial Universitaria Santiago, 1992, pp. 124 $-139)$.

20 Lechner, Norbert. "De la Revolución a la Democracia. El Debate Intelectual en América del Sur". Revista Opciones, n ${ }^{\circ}$, Santiago, mayo-agosto 1985, pp. 61, 65. 


\section{La Democracia Trivial}

Hoy, el contexto puede ser perfectamente otorgado por los imperativos coyunturales de poder del sector político donde actúen, aún en una sociedad abierta. Es reforzado, además, por dietas parlamentarias onerosas y privilegios sociopolíticos y judiciales; por su inserción en un tiempo-eficiencia que tensiona la cotidianeidad enmascarando en no poca medida la existencia de otra guerra, según ya expresé, una de sobrevivencia económica individual que evita la mirada de la"otredad" circundante, inmersa en tiempos-eficiencias distintos; por la aplicación de una doctrina de carácter neoliberal con insuficientes matices sociales asistenciales, que legitima una sensibilidad social en función de los macroequilibrios económicos ocultándoles todo cuestionamiento de sus consecuencias a niveles sociales más cotidianos; por la falta de un proyecto nacional consensuado que enmarque su acción ${ }^{21}$; por la casi completa ausencia de una prensa y educación críticas.

Especialmente importante en la conformación del contexto descrito son los acuerdos, o como quiera denominárseles, de fines de los ochenta y comienzos de los noventa de las elites para modelar la "transición" desde el autoritarismo cívico-militar del régimen militar al actual autoritarismo civil"22, lo que remite "no sólo al problema de los enclaves autoritarios, sino más bien, y sobre todo, a la cuestión de la ciudadanía... - pues - ... nada garantiza que la democracia chilena abandone su calificativo de incompleta, en la medida en que es posible hipotetizar que, más que una transición, lo que Chile ha vivido es

21 Los Cambios de Chile en Treinta Años. Garretón, Manuel Antonio. Pp. 107 - 115 (en: "Encuentros con la Memoria". LOM Ediciones, Santiago, 2004).

22 Una síntesis cronológica de los efectos de estos acuerdos en La Impunidad Durante la Transición. Chile 1990 - 2003. VII Informe Comisión Ética Contra la Tortura. Santiago, diciembre 2003. También en Portales, Felipe. Chile, Una Democracia Tutelada. Editorial Sudamericana, Santiago, 2000, pp. 49-85. 
la paulatina naturalización de un modo de organización política y social" ${ }^{23}$.

Por supuesto, lo anterior implica la manipulación sistemática de aquellos contenidos históricos que permitan cuestionar semejante tendencia, una manipulación que permite construir un "olvido" determinado en función de los intereses recién mencionados de las elites ${ }^{24}$.

El anterior contexto los proyecta operando sólo en función de específicas microcoyunturas que psicológicamente les otorgan un parámetro determinado de normalidad, una atmósfera psíquica particular, una "burbuja", desarrollando de esta forma un accionar político democrático sólo restringido a intereses particulares y no comunitarios; en el fondo, articulando una "democracia trivial" más manipulable y permisiva; en el fondo, autoritaria. Es por ello que creo que el dispositivo de poder analizado, tanto en el período en estudio como en la actualidad, no es más que la recreación o profundización de un ethos político autoritario que, lejos de desaparecer, adquiere ropajes distintos en las elites de turno. Si hoy ellas no han cuidado la conservación

23 Menéndez-Carrión, Amparo - Joignant, Alfredo. "De la "Democracia de los Acuerdos" a los Dilemas de la Polis: ¿Transición Incompleta o ciudadanía Pendiente?. (En: La Caja de Pandora, Menéndez, Amparo-Carrión - Joignant, Alfredo (editores). Editorial Planeta, Santiago, pp. 38, 44). Un análisis más amplio y detallado de este proceso en Portales, Felipe. Chile..., op. cit.

24 Existen dos aspectos centrales. Se debe considerar que, en cuanto a la violación de los Derechos Humanos se refiere, y aún comprendiendo que no eran sus objetivos - posiblemente el principal era ritualizar gradualmente la memoria de la violencia -, el Informe Rettig, la Mesa de Diálogo y el Informe Valech no han generado efectos jurídicos disuasivos de importancia para las elites que trabajaron en el régimen militar. Si bien han permitido paulatinamente ir dando a conocer cuánto ocurrió, la impunidad ha menoscabado estas percepciones. Por otro lado, pero en íntima relación con lo anterior, tampoco se debe olvidar que ni siquiera se ha insinuado la generación de una suerte de Informe Rettig que describa los abusos económicos y el enriquecimiento ilícito de las elites estudiadas. Considero que las cuentas bancarias descubiertas en EEUU a Pinochet (Ver Revista Siete +7, n 120, 121, 122, 125,129, julio, septiembre, 2004; diario La Nación, 3 de abril 2005, "Las Cuentas de Pinochet. Informe Completo del Senado de Estados Unidos", suplemento Temas de la Nación, 32 páginas) constituyen sólo una mínima expresión del tema en cuanto al régimen militar se refiere - pienso en la elite militar y, sobre todo, en los civiles que trabajaron en su gobierno o se relacionaron ventajosamente con el régimen, especialmente, aunque no únicamente, quienes ejercieron labores relacionadas con aspectos económicos -. 
de un imaginario ${ }^{25}$ que les dificulte, al menos, incurrir en la repetición de los niveles de "barbarie" ${ }^{26}$ desarrollados en el régimen militar, entonces reiteran en otros contextos - el de una "democracia trivial" - los elementos básicos que posibilitaron la emergencia histórica del régimen militar y del "Factor Pinochet", aunque, reitero, con ropajes distintos, pero con héroes similares.

25 Ver: Lechner, Norbert - Güell, Pedro. "Construcción Social de las Memorias en la Transición Chilena” (En: La Caja de Pandora, Menéndez, Amparo-Carrión - Joignant, Alfredo (editores), op. cit., pp. 185-210).

26 Pensamos en la palabra "barbarie" para describir en nuestro contexto de estudio un hecho concreto: cuando el militar profesional, experto en el uso sistemático y racional de la violencia, excede su uso para el cumplimiento de sus objetivos estrictamente militares. Esta gratuidad, entonces, se torna sistemática, lo que refleja que su aparente descontrol jerárquico se legitima, y que, por lo tanto, se convierte en un método militar aceptado y no cuestionado. Imperan elementos a-racionales como el odio, la ambición, en este caso "profesional" por escalar posiciones en función de méritos adquiridos por la ejecución de este tipo de servicios, la venganza y la perversión en las formas de castigo y aniquilación del enemigo. 